\title{
Extreme summer temperatures in Iberia: health impacts and associated synoptic conditions
}

\author{
R. García-Herrera ${ }^{1}$, J. Díaz ${ }^{2}$, R. M. Trigo ${ }^{3}$, and E. Hernández ${ }^{1}$ \\ ${ }^{1}$ Dto. Física de la Tierra II, Facultad de Físicas, Universidad Complutense, Spain \\ ${ }^{2}$ Centro Universitario de Salud Publica, Universidad Autónoma de Madrid, Spain \\ ${ }^{3}$ CGUL, Faculdade de Ciências, Universidade de Lisboa, Portugal
}

Received: 17 March 2004 - Revised: 25 October 2004 - Accepted: 27 October 2004 - Published: 28 February 2005

\begin{abstract}
This paper examines the effect of extreme summer temperatures on daily mortality in two large cities of Iberia: Lisbon (Portugal) and Madrid (Spain). Daily mortality and meteorological variables are analysed using the same methodology based on Box-Jenkins models. Results reveal that in both cases there is a triggering effect on mortality when maximum daily temperature exceeds a given threshold ( $34^{\circ} \mathrm{C}$ in Lisbon and $36^{\circ} \mathrm{C}$ in Madrid). The impact of most intense heat events is very similar for both cities, with significant mortality values occurring up to 3 days after the temperature threshold has been surpassed. This impact is measured as the percentual increase of mortality associated to a $1^{\circ} \mathrm{C}$ increase above the threshold temperature. In this respect, Lisbon shows a higher impact, $31 \%$, as compared with Madrid at $21 \%$. The difference can be attributed to demographic and socio-economic factors. Furthermore, the longer life span of Iberian women is critical to explain why, in both cities, females are more susceptible than males to heat effects, with an almost double mortality impact value.

The analysis of Sea Level Pressure (SLP), $500 \mathrm{hPa}$ geopotential height and temperature fields reveals that, despite being relatively close to each other, Lisbon and Madrid have relatively different synoptic circulation anomalies associated with their respective extreme summer temperature days. The SLP field reveals higher anomalies for Lisbon, but extending over a smaller area. Extreme values in Madrid seem to require a more western location of the Azores High, embracing a greater area over Europe, even if it is not as deep as for Lisbon. The origin of the hot and dry air masses that usually lead to extreme heat days in both cities is located in Northern Africa. However, while Madrid maxima require wind blowing directly from the south, transporting heat from Southern Spain and Northern Africa, Lisbon maxima occur under more easterly conditions, when Northern African air flows over the central Iberian plateau, which had been previously heated.
\end{abstract}

Key words. Meteorology and atmosphere dynamics (Meteorology and atmosphere dynamics)

\section{Introduction}

Classically, mortality has been considered as an indicator of population health. Various studies in different countries indicate seasonal behaviour of daily mortality as a function of diverse environmental variables, especially temperature (Montero et al., 1997; Alberdi et al., 1998; Keatinge et al., 2000), in a V-shape relationship (Kunst et al., 1993; Sáez et al., 1995). When specific causes of mortality are taken into account it is found that increased winter and summer mortality are mostly due to cardiovascular diseases, especially in the elderly (Pan et al., 1995; Alberdi and Díaz, 1997). This is coherent with the underlying biological mechanisms (Pan et al., 1995), which show that thermal susceptibility increases with advancing age. Reduced thermoregulatory responses and less sensitive thermal perception may blunt thermoregulatory behaviour during heat stress, which might in turn aggravate cardiovascular disease risks factors and trigger events such as thrombosis, strokes or Cardio Vascular Accidents. Much interest has been focused on the study of the health impact produced by extreme temperature events. Thus, in recent years there have been an increasing number of studies dealing with the mortality associated with intense heat events (e.g. Smoyer (1998), Nakai et al., 1999; Ungar (1999); Dessai (2002); Díaz et al., 2002a, 2002b; Davis et al., 2003). Readers looking for an updated review of methodologies and results are referred to Laschewski and Jendritzky (2002) and to Koppe et al., 2004. Results obtained by most of these authors agree on two key issues: a) the heat impact occurs at very short term, with the increased mortality lagging the heat wave by 1 to 3 days, b) people older than 65 are the most sensitive to extreme heat wave episodes. 
Global mean temperature has risen around $0.6^{\circ} \mathrm{C}$ over the last 100 years (IPCC 2001) and this increase has been sharper over the continents and milder over the oceans. Furthermore, over most continental landmasses, this warming has been asymmetrical, with trends of minimum night temperature being consistently of a higher magnitude than the trends of daily maximum temperature (Karl et al., 1993). A recent pan-European project (European Climate Assessment, ECA) has shown evidence of changes in the frequency of extreme temperatures during the second part of the 20th Century (Klein-Tank et al., 2002; Frich et al., 2002). Results obtained for the Iberian Peninsula confirm a steep increase of the minimum temperature and a smaller but, nevertheless, important raise of the maximum temperature (Santos et al., 2002). Furthermore, the concentration of population in large urban areas such as Lisbon and Madrid, with its urban heat island effect, is likely to further exacerbate the health impact of such temperature increases. Climate change community awareness to changes of summer heatwaves gained particular "momentum" with the catastrophic heatwave observed in the summer of 2003 in Europe. While the whole summer of 2003 was characterised by warm weather throughout Europe (Luterbacher et al., 2004; Schär et al., 2004), it was the relatively short-lived heatwave that occurred during the first fortnight of August 2003 that had a major impact in excessive mortality rates throughout western Europe, particularly in France (Grynszpan, 2004).

Lisbon, the capital of Portugal (10.4 million inhabitants), is located at the mouth of the Tagus River, and its metropoli$\tan$ area encloses approximately 2 million people; its climate is usually mild in the winter and warm in the summer, modulated by the nearby presence of the Atlantic Ocean. Madrid is the capital of Spain (40 million inhabitants) and is located at the very center of the Iberian Peninsula. Madrid's metropolitan area encloses approximately 3 million people and its climate is more continental than Lisbon, with frequent hot summer days and cold winter nights.

Most of the previously mentioned studies analyse the temperature-mortality relationship through the application of different statistical models. However, few of these works investigate in depth the atmospheric large-scale circulation that leads to such extreme conditions over specific regions of the globe. In recent years, one of the most promising methodologies has focused on the establishment of robust links between different air-mass types or atmospheric weather situations, and the associated effects on human health at a local or regional scale. Most applications were developed for sites located in the USA (Kalkstein, 1991; Kalkstein and Smoyer, 1993; Greene and Kalkstein, 1996), including a warning system for the Philadelphia area (Kalkstein et al., 1996). Similar approaches have now been adapted to other regions, such as England (McGregor et al., 1999) and Australia (Guest et al., 1999). Previous work for the Iberian Peninsula (García et al., 2002) has looked at specific synoptic conditions leading to Extremely Hot Days (EHD) in the area of Madrid, Spain, revealing that stagnation episodes and southern fluxes are the most relevant patterns.
The characterization of the synoptic patterns involved in the occurrence of mortality events is especially relevant because atmospheric circulation indices at the synoptic scale are nowadays well reproduced by regional circulation models and thus can be satisfactory used as forecast tools. In fact, an adequate real-time forecasting scheme, either statistical or dynamical in nature, is the most useful tool to prevent the increased health risks of extreme heat episodes. However, the role of local meteorological factors (e.g. sea breezes, topography, nearby lakes or mountains) is far from being completely understood, thus a better understanding of these factors could yield the development of better downscaling schemes which would provide an increment on the quality of forecasts.

The main aims of this paper are twofold: a) to examine the effect of Extremely Hot Days (EHD) on mortality in Lisbon and Madrid, and b) to characterize the meteorological factors that lead to an increase in summer heat-related mortality for both Iberian cities. Previous studies for Iberia have analysed the association between mortality and extreme temperatures in both cities, but with different methodologies; Box-Jenkins for Madrid (Díaz et al., 2002a) and a simple empirical model for Lisbon, (Dessai, 2002). This precluded a direct comparison of the results. The simultaneous analysis presented here should be beneficial to detect the differences due to the local meteorology and social variables, by using the same methodology applied to similar meteorological and mortality series. Furthermore, it should be stressed that none of the previously mentioned works has analysed the synoptic atmospheric circulation characteristics that led to an EHD in Lisbon. On the other hand, the only work that has looked at atmospheric circulation leading to EHD in Madrid (García et al., 2002) lacks the comprehensive multivariable approach presented here.

Data and the methodology are briefly introduced in Sect. 2. Then, Sect. 3 characterises the health impact of EHDs in both Madrid and Lisbon using a Box-Jenkins methodology. Section 4 describes in great detail the similarities and the differences of the atmospheric synoptic patterns responsible for EHD in Lisbon and Madrid. Finally, a discussion and some conclusions are outlined in Sect. 5.

\section{Data and methods}

Among the different methodologies available to evaluate the health impact of environmental variables, two techniques stand out as those most commonly used: generalised additive models (Kelsall et al., 1997) and Box-Jenkins models (Box et al., 1994). A recent study shows that both of them produce similar results when the considered populations follow normal distributions (Tobías et al., 2001). Box-Jenkins or ARIMA models present the additional advantage that they can provide the results expressed as the absolute increase of mortality associated with an increase in temperature of $1^{\circ} \mathrm{C}$. This may be more easily manageable than the relative risks given by the additive models. Basically, these BoxJenkins or ARIMA models take into account the history of 
the modelled series through autorregresive (AR) and moving average (MA) terms. The external variables can be introduced linearly at varying lags and dealing with different simultaneous effects, thus enabling an effective identification of the individual role associated with each specific predictor.

When analysing the association between extreme temperature and mortality, it must be noted that the mortality seasonal cycle is probably not associated with temperature (Lasheweski and Jendritzky, 2002; Davis et al., 2004). In order to remove the spurious signal from the seasonal cycle both series have been fitted to an ARMA model, ARMA $(2,0,2)$. The residuals have then been correlated at different time-lags. The significant values, after applying a Chisquare test (Makridakis et al., 1983), will show which mortality peaks are associated with high temperature events. A more detailed description of the methodology followed in this paper can be found in Díaz et al. (1999).

Mortality has been computed as the number of daily deaths occurring in Madrid and Lisbon between 1986 and 1997 from June to September, both inclusive. The considered causes were "organic" (all mortality causes excluding accidents) included under the codes ICD9 1-799. The resident population of both metropolitan areas has not changed significantly during these 12 years, so results are represented in terms of raw mortality as performed in previous works for this two cities (Dessai, 2002; Díaz et al., 2002a), since the interest lies in evaluating the absolute impact. However, there are no significant differences when we apply the same methodology to standardised rates (not shown). The meteorological variables included in the models are daily maximum, minimum and average temperatures. Station-based meteorological variables were obtained from the Retiro Observatory in Madrid and from the Instituto Geofísico D. Luis in Lisbon. It should be emphasised that both meteorological stations are located near the city centres (Table 1) and that these data have been used extensively in several previous interdisciplinary studies, taking advantage of their long and consistent records, as well as data control procedures (e.g. Dessai 2002; Diaz et al., 2002a).

To obtain a comprehensive, multivariable characterisation of the atmospheric circulation associated with the extreme temperatures, NCEP/NCAR reanalysis data (Kalnay et al., 1996) for the summer season (June and September), for the period 1958-1997 has been used. In order to identify the most favorable synoptic conditions to EHD, several surface, low- and mid-tropospheric meteorological variables were considered. Anomaly fields of surface or low troposphere climate variables are then computed and interpreted based on large-scale physical mechanisms, such as the advective anomalous mean flow (characterised by the $500 \mathrm{hPa}$ geopotential height and the surface wind) or the radiative balance associated with anomalous cloud cover (Trigo et al., 2004). Despite the relative small size of Iberia we have opted to extract a large window $\left(30^{\circ} \mathrm{W}-15^{\circ} \mathrm{E}\right.$ and $\left.30^{\circ} \mathrm{N}-60^{\circ} \mathrm{N}\right)$ that includes most of Western Europe, part of Northern Africa and a large sector of the Northern Atlantic ocean. The meteorological data used consist of time series of daily values of:
1. sea level pressure (hereafter SLP),

2. $500 \mathrm{hPa}$ geopotential height,

3. $850 \mathrm{hPa}$ level temperature,

4. maximum and minimum air temperature at $2 \mathrm{~m}$ (hereafter $\mathrm{T}_{\max }$ and $\mathrm{T}_{\min }$ ),

5. zonal and meridional wind components at $10 \mathrm{~m}$,

6. precipitation rate.

It must be remembered that, though based on observational data, the reanalysis data is also dependent upon the skill and reliability of the particular forecast model used. In the case of NCEP/NCAR reanalysis, Kalnay et al. (1996) categorise the reliance on the model of different types of variables. According to these authors variables such as SLP, $500 \mathrm{hPa}$ geopotential height and $850 \mathrm{hPa}$ temperature correspond to observed variables that were analysed by the model, while precipitation rate is most dependent upon the forecast model, thus susceptible to model systematic errors and must be used with precaution. Nevertheless, it is necessary to bear in mind that all the large-scale atmospheric circulation analyses performed in this paper were based on the use of anomaly composites (mean field removed), thus filtering considerably the impact of model inadequacies on our results (Trigo et al., 2004).

The definition of what constitutes an EHD day will avoid the use of absolute threshold values, such as the common definition of any day with $\mathrm{T}_{\max }>30^{\circ} \mathrm{C}$ or $\mathrm{T}_{\max }>35^{\circ} \mathrm{C}$. Here, EHD will be selected on a local basis, taking into account the temperature-mortality relationships for each city and also the characteristics of the corresponding local $\mathrm{T}_{\max }$ distribution. In particular, an EHD will be defined as any day with a $\mathrm{T}_{\max }$ value above the 95 percentile value of $\mathrm{T}_{\max }$ for that particular station (see next section for details). The computation of these 95 thresholds and consequently the EHD sequences will be performed twice, the first time with the "short" period of 1986-1997 for the heat-mortality assessment and then with the "longer" period of 1958-1997 for the large-scale synoptic characterization. It is worth mentioning that we are not using a heatwave definition, usually based on the intensity and/or duration of consecutive number of days above a certain threshold. If we had been restricted to only those events with more than three or five days, it would have limited the application of the above-mentioned ARIMA models. In this sense this work focuses its attention on describing the impact of higher than usual temperatures, regardless of whether they occur in a sequence or as isolated events. Thus, the term heatwave will be only employed here whenever our results are compared with those obtained by other authors that have effectively used heatwave definition.

\section{Mortality versus extreme temperatures}

All the analysis developed in this section is based on data for the short period that spans between 1986 and 1997. The as- 
Table 1. Summary of main characteristics of data used from Lisbon and Madrid. Comparison of different variables between Madrid and Lisbon.

\begin{tabular}{lll}
\hline & Madrid & Lisbon \\
\hline Population considered (Census of 1991) & 3.0 million people & 2.0 million people \\
Latitude/Longitude/Altitude & $40^{\circ} 41^{\prime} / 3^{\circ} 67^{\prime} / 665 \mathrm{~m}$ & $38^{\circ} 43^{\prime} / 9^{\circ} 08^{\prime} / 77 \mathrm{~m}$ \\
Meteorological Station used & Retiro (city center) & Instituto de Geofisica D.Luis (city center) \\
Short Period & $1986-1997$ & $1986-1997$ \\
Temperature Threshold (95 percentile for short period) & 36.4 & 33.6 \\
Long Period & $1958-1997$ & $1958-1997$ \\
Temperature Threshold (95 percentile for long period) & 35.7 & 33.4 \\
Most frequent duration of EHD spells/(Maximum duration) & $1-2$ days (11 days) & $1-2$ days (6 days) \\
\hline
\end{tabular}

Table 2. Temperature impact for both cities.

\begin{tabular}{lll}
\hline & Madrid & Lisbon \\
\hline Lags with significant correlations & Both genders: 0,1,2,3( maximum effect 1) & Both genders: 0,1,2,3 (maximum effect 1) \\
& Males: 0,1,3 (maximum effect 1) & Males: 0,1,2 (maximum effect 1) \\
& Females: 0,1,2,3 (maximum effect 1) & Females: 0,1,2,3 (maximum effect 1) \\
$\begin{array}{l}\text { Percentage of increase } \\
\text { of mortality for } 1^{\circ} \mathrm{C} \text { increase } \\
\text { above temperature threshold }\end{array}$ & Both genders: 21,5\% & Both genders: 31,3\% \\
& Males: $15,9 \%$ & Males: 21,7\% \\
\hline
\end{tabular}

sociation between mortality and daily maximum, minimum and average temperatures was evaluated by applying ARIMA models. This preliminary analysis allowed for the identification of daily maximum temperature $\left(\mathrm{T}_{\max }\right)$ as the thermal variable more closely associated with mortality in both cities. Minimum temperature also showed a significant association, but with lower values than those obtained for $\mathrm{T}_{\max }(-0.17$ vs. -0.12 values for the correlation coefficients between daily mortality and $\mathrm{T}_{\max }$ and $\mathrm{T}_{\min }$, respectively) for Madrid. Similar values were obtained for Lisbon. Table 2 summarizes the most relevant results obtained for the association between mortality and extreme temperatures. As in previous works for Madrid (Díaz et al., 2002) and Lisbon (Dessai, 2002), the use of additional meteorological variables (e.g. $\mathrm{T}_{\min }, \mathrm{T}_{\max }-\mathrm{T}_{\min }$, relative humidity) does not add more information to the temperature-mortality analysis, possibly as a consequence of the very high values of cross-covariability between these variables. We have also obtained scatter diagrams for $\mathrm{T}_{\min }$ at Madrid and Lisbon (not shown). However, these figures do not indicate any clear threshold. In fact, unlike $\mathrm{T}_{\max }$, only the very upper values of the $\mathrm{T}_{\min }$ distribution are associated with high mortality. Thus, it seems that $\mathrm{T}_{\min }$ might play a significant role during particularly severe (and rare) heatwaves, but not during those less severe (and more frequent) Extreme Hot Days (EHD) events. The fact that the impact of $\mathrm{T}_{\min }$ is constrained to a limited number of days could then easily explain why the variable $T_{\min }$ is consistently (Lisbon and Madrid) considered not significant in any of the developed statistical models. The relationship between extreme temperature and mortality is first characterized through the dispersion diagram, which can be seen in Fig. 1. The solid line corresponds to a minsce method, with $50 \%$ of the points and 3-iteration adjustment, as included in the Statistical package SPSS 10.0. (Pardo and Ruiz, 2002).

This diagram represents, in a similar way to that provided by Davis et al. (2003), the daily mortality anomalies (computed as a $\%$ of the averaged daily value) versus the daily $\mathrm{T}_{\max }$ values. It is evident that both cities exhibit a very similar behaviour, with a steeper slope when a certain threshold is surpassed. A simple visual inspection of Fig. 1 reveals that, in both cases, there is a higher effect when maximum daily temperature exceeds a given threshold that is $2^{\circ} \mathrm{C}$ lower in Lisbon $\left(\sim 34^{\circ} \mathrm{C}\right)$ than in Madrid $\left(\sim 36^{\circ} \mathrm{C}\right)$ due to the proximity of Lisbon to the Atlantic Ocean, as compared with the continental location of Madrid. Furthermore, for both cities the threshold corresponds, roughly, to the 95 percentile of the daily maximum temperature series (Table 1) represented by the vertical line in Fig. 1. Thus, based on these empirical results we have included as an EHD all those days that verify values of $T_{\max }$ above the 95 percentile threshold, and for the considered period. The validity of this threshold is reinforced when total mortality is computed separately for the EHD and for the rest of the days (Table 2). Thus, in Madrid average daily mortality during EHDs is 93.7, while it is only 78.5 for the non-EHDs, the difference being significant at $p<0.05$ after a t-test and mostly attributable to women (47.7 vs. 37.5 deaths). 

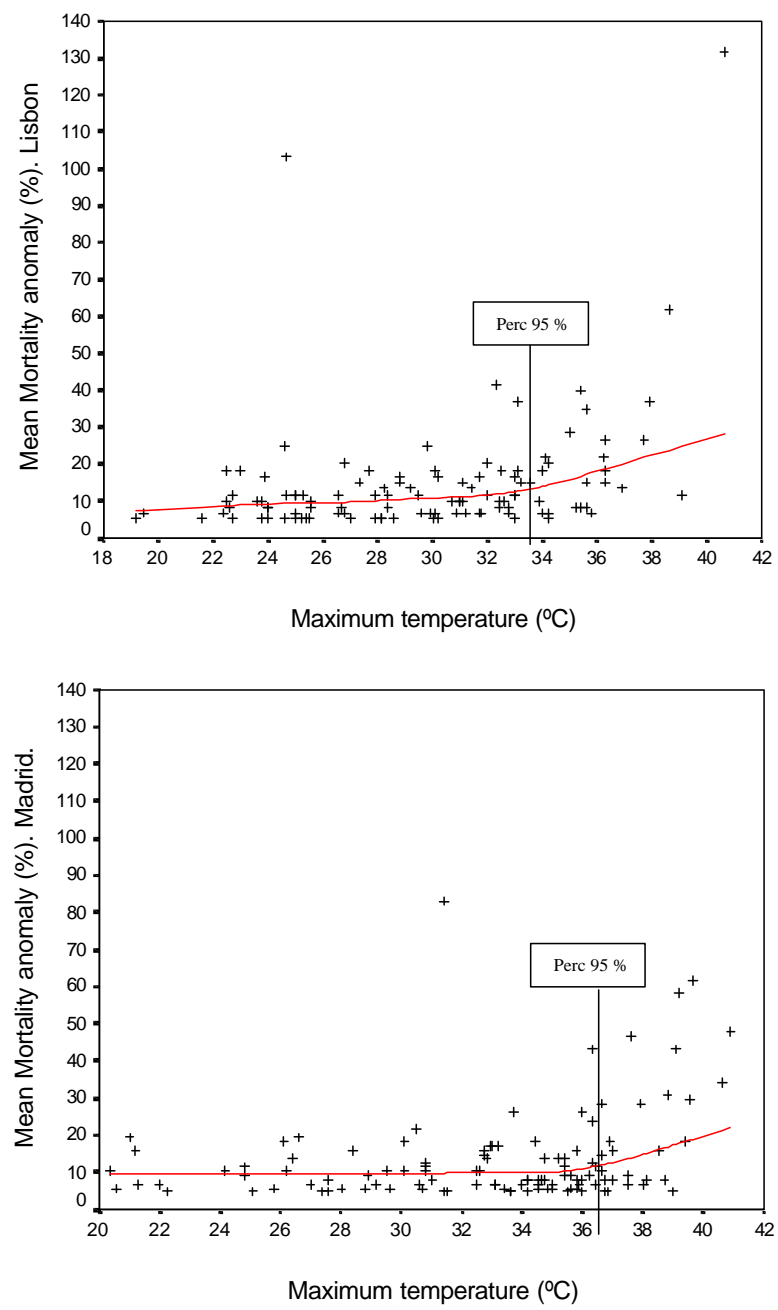

Fig. 1. (a) Daily mortality anomalies (anomalies $>0$ ) versus daily maximum temperatures for Lisbon. The solid line corresponds to a minsce method with $50 \%$ of the points and 3 iterations adjustment. The corresponding 95 percentile $\mathrm{T}_{\max }$ value for Lisbon is also represented. (b) Daily mortality anomalies versus daily maximum temperatures for Madrid. The solid line corresponds to a minsce method with $50 \%$ of the points and 3 iterations adjustment. The corresponding 95 percentile $\mathrm{T}_{\max }$ value for Madrid is also represented.

For Lisbon the results are qualitatively similar with 60.0 deaths for EHDs and 50.3 for non-EHDs (difference is significant at $\mathrm{p}<0.05$ ), women being responsible for $60 \%$ of the difference. For this temperature-mortality study the analysis has to be restricted to the 1986-1997 period because those are the years with available data for both Lisbon and Madrid. Nevertheless, the $\mathrm{T}_{\max }$ distributions are rather different, as can be seen in Fig. 2. The Madrid distribution is skewed to the right while Lisbon's corresponding distribution is skewed to the left. So there is not a simple shift in the same underlying distribution when we move from Lisbon to Madrid. While the difference, between both cities, in the mean is $2.5^{\circ} \mathrm{C}$ the corresponding difference in the median is much larger, almost $3.7^{\circ} \mathrm{C}$. Thus people in Madrid are really much
Daily maximum temperature $\left({ }^{\circ} \mathrm{C}\right)$

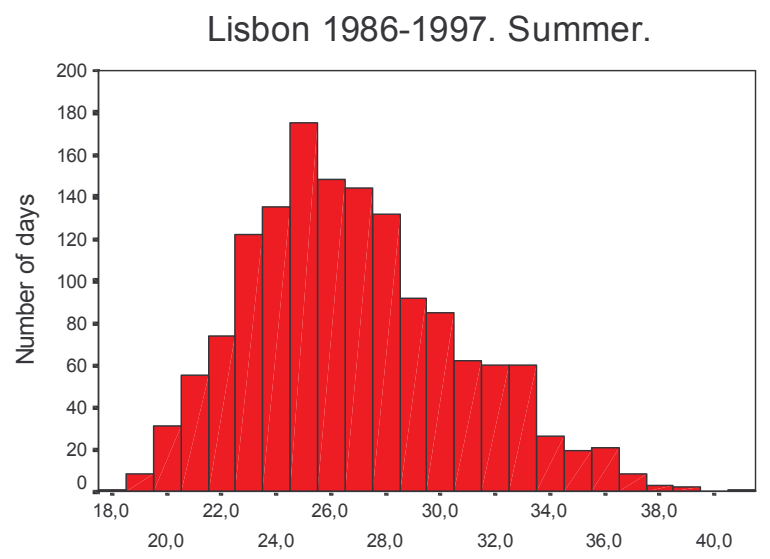

Daily maximum temperature $\left({ }^{\circ} \mathrm{C}\right)$

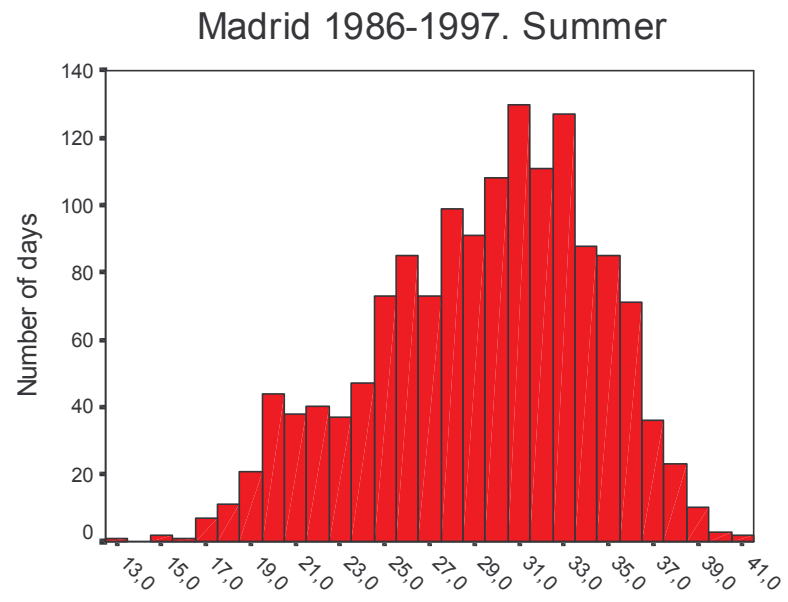

Fig. 2. Histograms of summer (JJAS) $\mathrm{T}_{\max }$ for Lisbon (upper pannel) and Madrid (lower pannel) for the short 1986-1997 period.

more accustomed to temperatures between $32^{\circ} \mathrm{C}$ and $38^{\circ} \mathrm{C}$ than in Lisbon. We believe that the similarity of both curves in Fig. 1, above the triggering threshold, is very important, as it could be associated with the intrinsic capacity for populations to accommodate for specific local conditions. The increase in deaths above this threshold is associated with a failure in the thermal acclimation mechanisms (Khaw, 1995). This effect is also suggested by Fig. 3, which shows the impact associated with the EHD, depending on their order of appearance within a given season. It can be seen that the first event of the season has the highest EHD impact, reflecting the well-known fact (Díaz et al., 2002a) that first heat events in the summer have a greater impact on the more susceptible individuals. The remaining and healthier population is then less impacted by the next events. It must be emphasized (not shown) that the incidence of EHDs occurs mostly as isolated events, with the majority of the EHD spells lasting one or two consecutive days ( $72 \%$ in Madrid and $75 \%$ in Lisbon). 


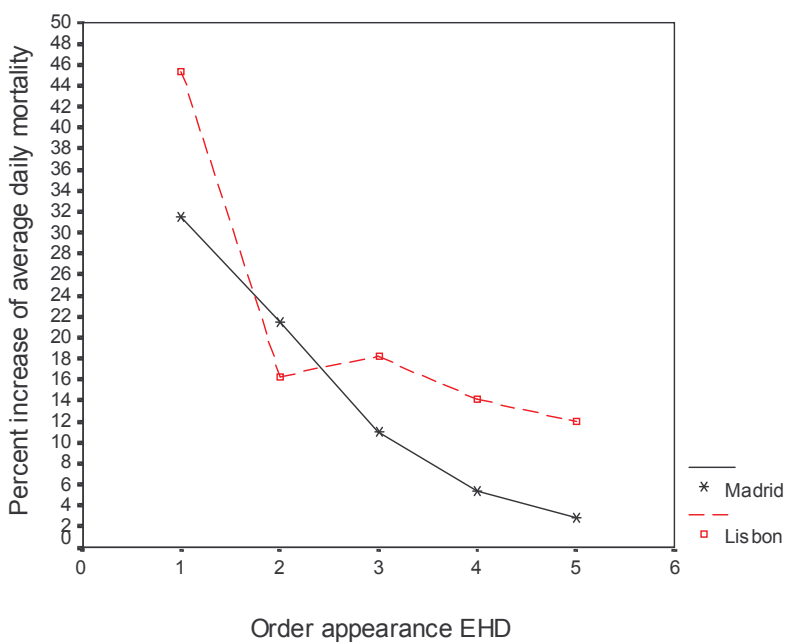

Fig. 3. Daily percent increase above the average mortality for Lisbon (dashed) and Madrid (solid) associated with an EHD, depending on the EHD order of appearance within the same season, for the short period 1986-1997.

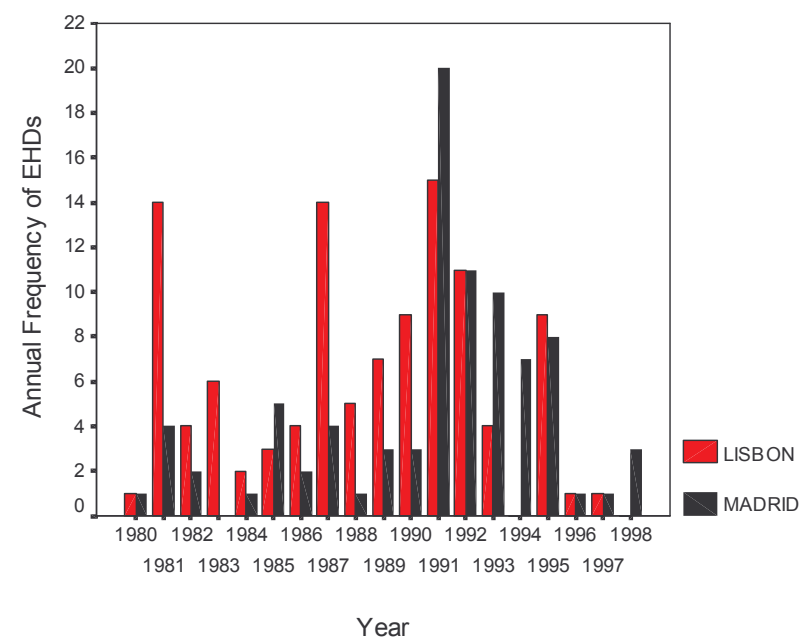

Fig. 4. Annual frequencies of EHDs for Lisbon (light columns) and Madrid (dark columns) for the longer periods of 1958-1997.

The longest duration observed is 11 days for Madrid and 6 days for Lisbon, for the 11-year period considered (Table 1).

The monthly distribution (not shown) shows some differences, generally EHD spells appear more concentrated in the peak summer months of July and August in Madrid (90\% of the total EHDs) than in Lisbon (75\%). For both cities, the temperature impact is significant up to 3 days after an EHD has occurred, as evident in Table 2, with the maximum occurring after one day, as would be expected due to the underlying biological mechanisms (Pan et al., 1995). More differences arise when the temperature effect is quantified (last row in Table 2), with Lisbon presenting a higher mortality impact, which could be attributed to socio-economic factors. Interestingly, the impact of EHD is especially relevant among women, with almost a $41 \%$ mortality increase as- sociated with a $1^{\circ} \mathrm{C}$ increase above the threshold. Demographic factors are the main explanation for these figures, as the longer life span of both Spanish and Portuguese women implicate for both cities many more women than men. This is because women older than 65 years are the more susceptible group to pathologies associated with extreme temperatures (Pan et al., 1995; Alberdi and Diaz, 1997). In Lisbon (Madrid), they account for 7.8\% (12.8\%) of the total population, while men older than 65 years account for just $5.7 \%$ in Lisbon (and 5.0 in Madrid), according to the 1991 census.

\section{Synoptic patterns}

The main purpose of this section is to identify and characterize the synoptic patterns associated with summer (JJAS) EHD in Lisbon and Madrid for the "longer" period that spans between 1958 and 1997. Again, the identification of EHD is based on station data for each city, while the characterization of the typical EHD configuration is achieved with the NCEP/NCAR reanalysis data set. We use the 40 -year period (1958-1997) of NCEP/NCAR reanalysis of summer data in order to attain more robust results than those we could obtain if we had opted for the "short" period (1986-1997) used in the previous section. Despite the lack of mortality data to cover this 40-year period, we decided to maintain the threshold rationale, i.e. that the vast majority of heat-related excessive deaths occur above the 95 threshold in both Lisbon and Madrid. Thus, the EHD days were selected after computing the 95 percentile value of $\mathrm{T}_{\max }$ for this longer period and for both cities. Although very similar, the 95 triggering threshold for both cities is slightly different from those obtained with the shorter period. The 95 percentile threshold for the longer time series corresponds to $33.4^{\circ} \mathrm{C}$ for Lisbon and $35.7^{\circ} \mathrm{C}$ for Madrid. For both cities, an EHD annual series was generated and these are represented in Fig. 4. It can be seen that they present a very different evolution, with the Lisbon series showing higher frequencies in the first part of the period, while Madrid shows higher values for the second part. In fact, the correlation between them is $r=0.53$, significant $(\mathrm{p}<0.05)$, but not as high as would be expected due to their proximity. This is also evident when we analyse the value of $\mathrm{P}_{\mathrm{EHD}}$ (Madrid/Lisbon) that corresponds to the conditional probability of an EHD in Lisbon, given that an EHD has occurred on the same day in Madrid. In fact, the attained value for this statistic is just $\mathrm{P}_{\mathrm{EHD}}$ (Madrid/Lisbon) $=0.19$. This value is rather low and suggests a heavy influence of regional and local factors; the analysis below further illustrates this point.

The composite analysis (Figs. 5-8) is based on averages obtained with these sets of 244 cases and their differences to the summer averages computed with the full 4880 days. We have made an effort to provide simultaneous representation of different fields in a way that facilitates the interpretation of climate impact anomalies based on dynamical fields, such as those provided by the corresponding 5\% composite of SLP, $500 \mathrm{hPa}$ geopotential height or the surface wind. 


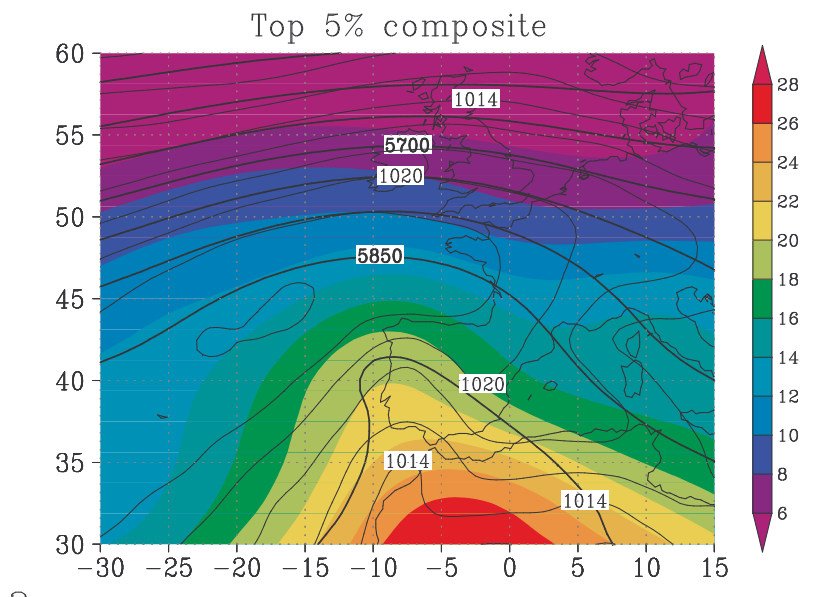

a
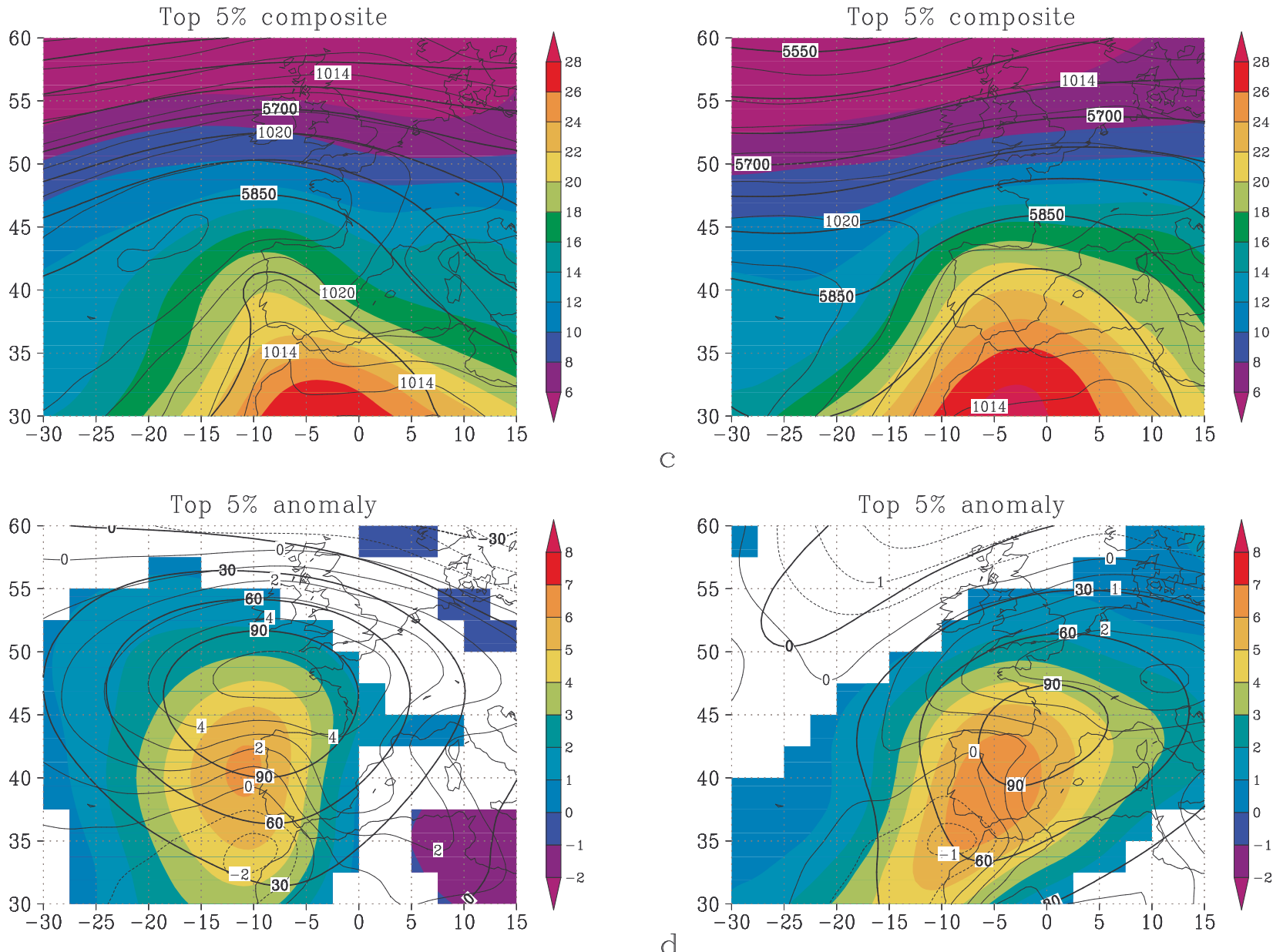

C

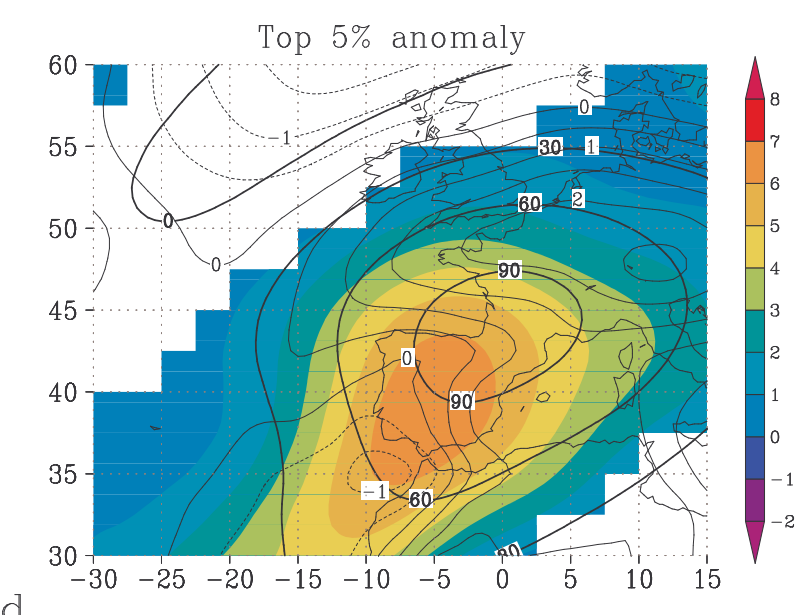

Fig. 5. Composites of $850 \mathrm{hPa}$ temperature in shaded colour $\left({ }^{\circ} \mathrm{C}\right.$ ), of SLP (mb, light curve) and $500 \mathrm{hPa}$ (gpm, bold curve) for the top $5 \%$ of maximum summer temperature in (a) Lisbon and (c) Madrid. All data correspond to the longer period between 1958 and 1997. The corresponding top 5\% anomaly composites, after removing the summer average, are represented in (b) Lisbon and (d) Madrid. The $850 \mathrm{hPa}$ temperature anomaly field is represented only in those areas where such an anomaly is significant at the 5\% level (or 95\% confidence level) computed with a two-tailed t-test.

Results are shown in a standard format, i.e. each figure presents composites of different variables for the top 5\% of maximum summer temperature in Lisbon and Madrid (panels a and c), and the corresponding top 5\% anomaly composite after removing the summer average (panel $b$ and $d$ ). Climate anomaly fields are represented only in those areas where such anomaly is significant at the 5\% level (or 95\% confidence level) computed with a two-tailed t-test. We took into consideration the existence of spatial autocorrelation when computing the degrees of freedom (dof), in order to apply correctly the t-test statistic. Here, dof were defined based on the number of significant PCs retained, for each variable, after applying a Principal Component Analysis (PCA), a statistical tool frequently employed to compute the dof of large-scale climatological fields. The PCA was applied to the correlation matrix of each climatic variable obtained for the entire 40-year period (summer months only) and over the window shown in Figs. 5-8. There is no single criterion that can be used to choose the number of principal components that ought to be retained in any given situation (Wilks, 1995). It is a common procedure to retain all variables until the total explained variance reaches a certain threshold, typically of the order of $80 \%$ or $90 \%$. Another possibility is to retain all PCs which individually account for more variation than the average variation in the original data set, i.e. to keep all PCs with corresponding eigenvalues higher than unity (Kaiser's rule). Such empirical rules are, by their very nature, subjective and can lead to different interpretations by different authors (Trigo and Palutikof, 2001). In the present analysis an objective rule was applied, based on what is hopefully a more reliable statistical approach. The objective "N rule" divides the total variability into "signal" and "noise" components (North et al., 1982; Preisendorfer, 1988). In this analysis only the "signal" components are retained, i.e. those PCs that are statistically significant at the 5\% level. The number of PCs obtained that are statistically significant at the $5 \%$ level varies between five and eight, depending on the climate variable. However, taking into account the difficulty in 

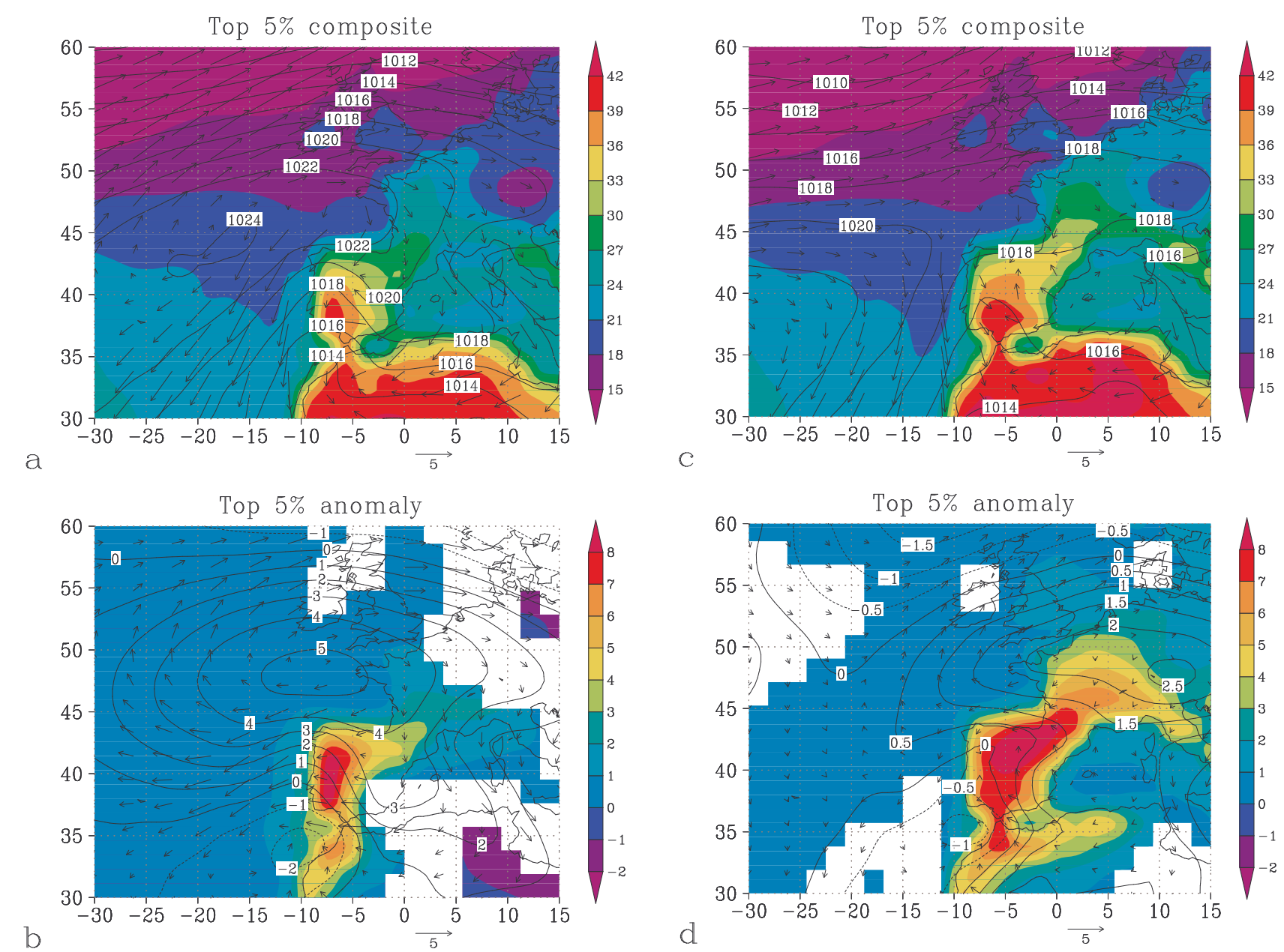

Fig. 6. Composite of $\mathrm{T}_{\max }$ in shaded colour $\left({ }^{\circ} \mathrm{C}\right)$ for (a) Lisbon, and (c) Madrid. Contour lines and arrows show, respectively, the associated SLP (mb) and $10 \mathrm{~m}$ height wind (m/s) fields. All data correspond to the longer period between 1958 and 1977 . The corresponding top 5\% anomaly composites, after removing the summer average, are represented in (b) Lisbon and (d). The $\mathrm{T}_{\text {max }}$ anomaly field represented only in those areas where such an anomaly is significant at the 5\% level (or 95\% confidence level) computed with a two-tailed t-test.

interpreting the synoptic characteristics of the modes above $\# 5$, the number of modes retained for the present study was restricted to the first five PCs for all variables. It is important to mention that the use of empirical rules, such as retaining all the modes with eigenvalues above one, implies more PCs being retained. Thus, the emphasis of the present section is to characterise climate and dynamical patterns of the synoptic atmospheric circulation which lead to EHD and to assess how significantly different these patterns are from summer climatology.

Figure 5 shows that, in Lisbon, the impact of the $5 \%$ composite on the $850 \mathrm{hPa}$ temperature field is related to the corresponding field of SLP and $500 \mathrm{hPa}$ geopotential height. The usual summer configuration of the Azores high is enhanced, extending further west and linking with the high pressure system located in Western Mediterranean (Fig. 5a). Moreover, while mid-tropospheric circulation, represented by the $500 \mathrm{hPa}$ geopotential high isolines configuration; at higher latitudes presents a zonal-flow configuration, the Iberian re- gion is affected by a strong ridge with the flow presenting an important meridional component. For Madrid, the anomalies are less intense, but extending over a larger area (Fig. 5c). The ridge over Iberia shows less sharp contours, but higher anomaly values, as suggested in Fig. 5d. It seems that extreme values in Madrid require a more western location of the Azores high, embracing a greater area over Europe, even if it is not as deep as for Lisbon.

Significant and highly symmetrical temperature anomalies can be seen over Western Iberia, with the maximum $\left(\sim 6.5^{\circ} \mathrm{C}\right)$ on the western coast near Lisbon (Fig. $\left.5 b\right)$. The spatial extent of the $850 \mathrm{hPa}$ temperature anomaly field can be explained with the corresponding anomalous SLP field (Fig. 5b). In fact, the SLP anomaly field presents a strong positive anomaly north of the Peninsula, with an extension into the Western Mediterranean, and a smaller, but important negative anomaly located between Portugal and Morocco. Both synoptic features contribute to the advection of warm and dry air from Northern Africa. Interestingly, 

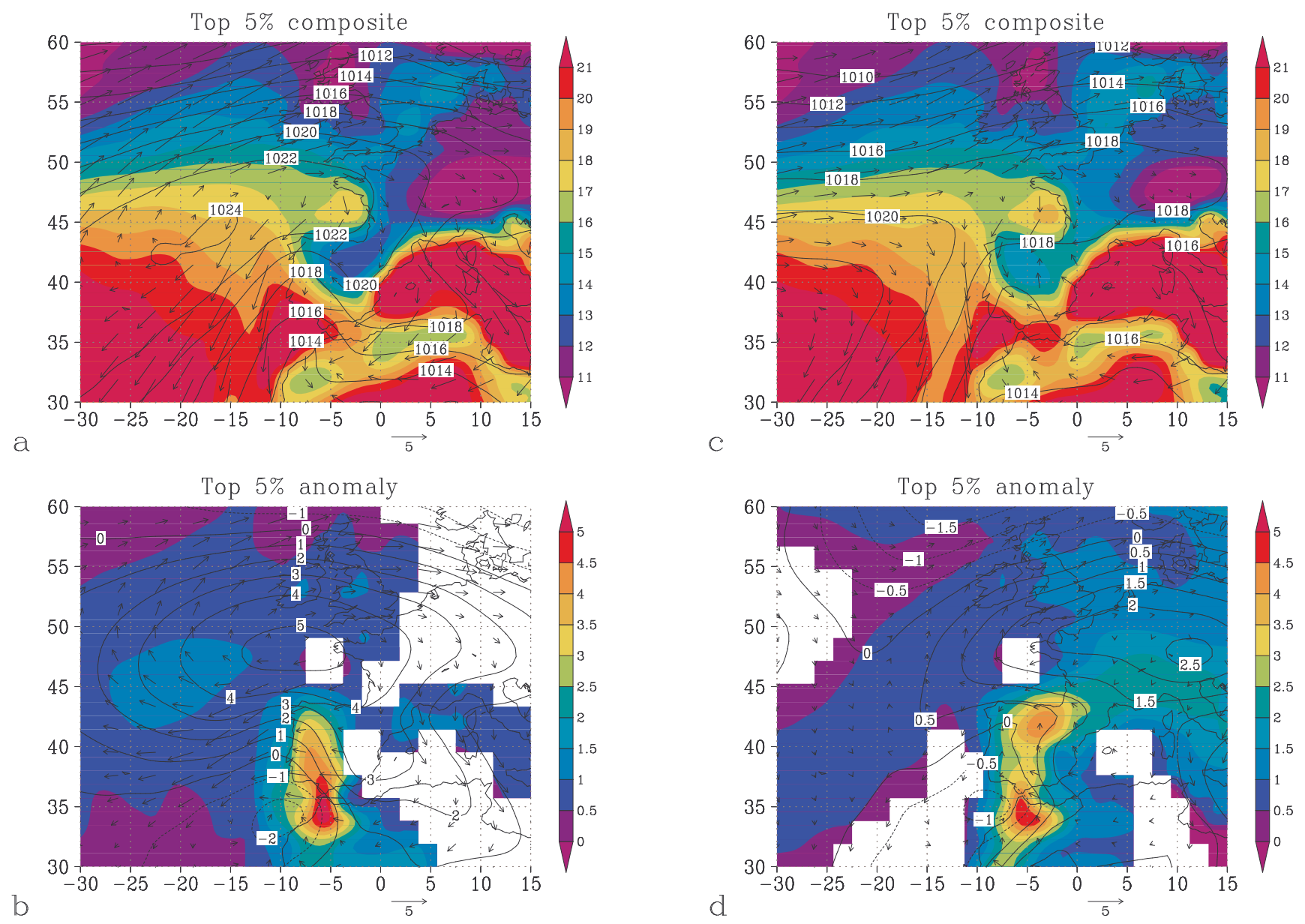

Fig. 7. As Fig. 6 but for $\mathrm{T}_{\min }$.

the corresponding anomaly field for the $500 \mathrm{hPa}$ geopotential height only presents the positive anomaly located north of the Peninsula (Fig. 5b). Nevertheless, such a result is consistent with the typical summer lows that develop over or near the Iberian Peninsula in the summer; most of these lows are very shallow and do not develop into the middle/high troposphere (Trigo et al., 2002). For Madrid, the $850 \mathrm{hPa}$ temperature anomaly field is, again, slightly more intense and covering a wider area (Fig. 5d), being located more westwards and covering most of Iberia. Nevertheless, the key aspects linking dynamical mechanisms and associated low troposphere climate anomalies are similar, to those described for Lisbon (García et al., 2002).

As expected, the impact of the Lisbon's 5\% composite on NCEP $\mathrm{T}_{\max }$ field, although impressive over western Iberia, is considerably less symmetrical than the one obtained for the $850 \mathrm{hPa}$ temperature. In fact, the $\mathrm{T}_{\max }$ anomaly field presents a large maximum higher than $8^{\circ} \mathrm{C}$ over western Iberia (Fig. 6a), where the 5\% composite temperatures can reach $40^{\circ} \mathrm{C}$ (Fig. 6b). Significant differences can be seen throughout most of Western Europe extending from southern UK to Morocco. Interestingly, anomaly grids situated over the Atlantic Ocean are also considered to be significant, de- spite their small magnitude. On the contrary, the relatively high anomaly value observed in the south-eastern corner of the Peninsula is considered not significantly different from the summer average, possibly due to high variability. For Madrid, $T_{\max }$ anomalies exhibit a more western location over central Iberia and more extended over North Africa, indicating the higher influence on the African conditions on Madrid extremes (Fig. 6c). The anomaly surface wind field is in good agreement with the corresponding SLP anomaly fields, confirming the origin of the intense heat advection from Northern Africa and across the central Iberian plains towards the western coast where Lisbon is located (Fig. 6b), or correspondingly, a more meridional character, from North Africa and Southern Iberia onto Madrid (Fig. 6d). It is worth noting that the wind anomalies for Madrid are much smaller than those for Lisbon. This is important and confirms that many EHD in Madrid are observed either during weak southerly wind conditions or even stagnation episodes (García et al., 2002). On the contrary most EHD days in Lisbon are associated with relatively strong winds from Spain and an intensification of Azores Anticyclone, including its southward bound branch. Moreover, both wind fields exhibit some ageostrophic nature, responsible for the change in direction 

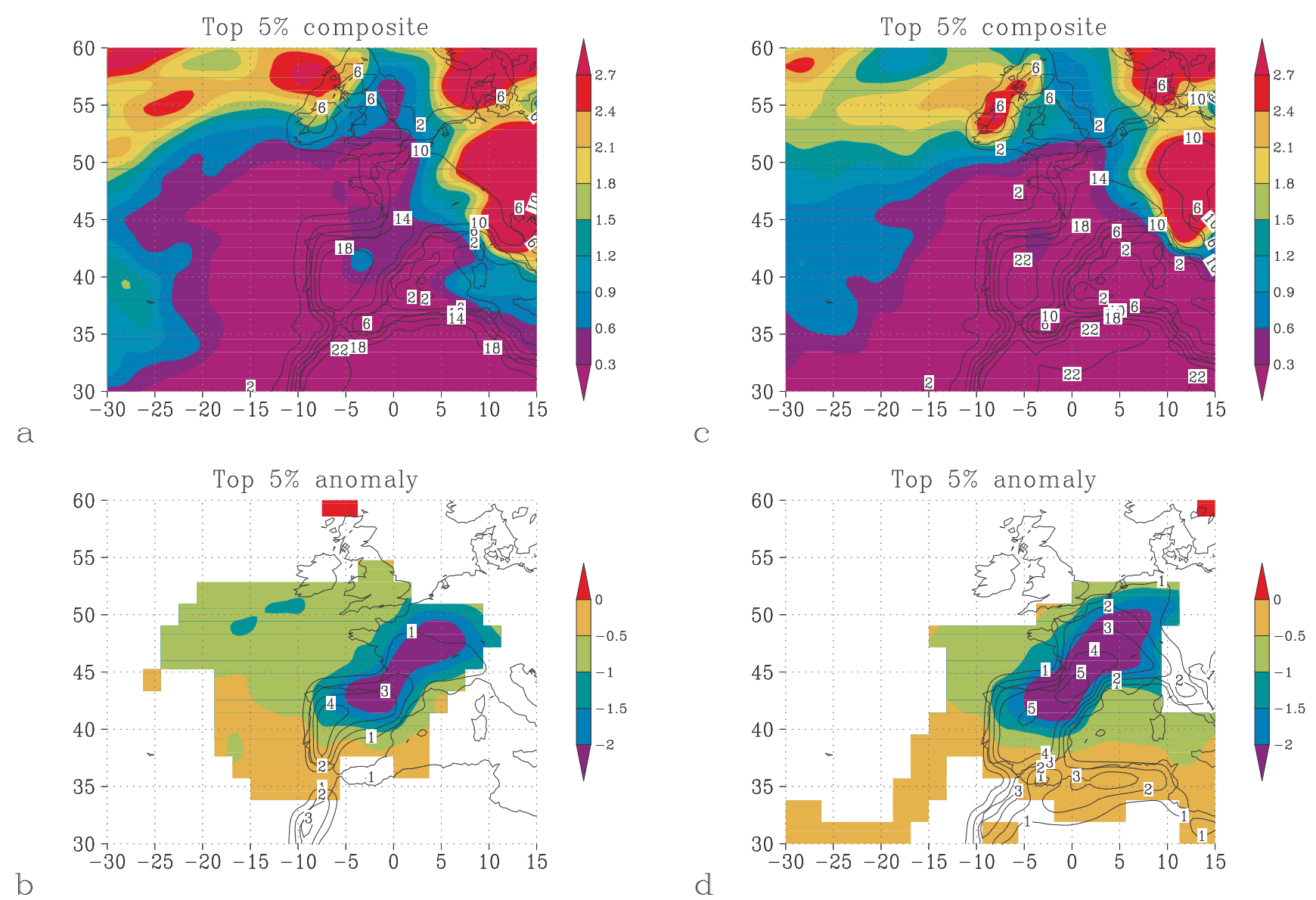

Fig. 8. Composite of precipitation rate in shaded colour (mm/day). For (a) Lisbon and (c) Madrid. Contour lines show the associated temperature range $\mathrm{T}_{\max }-\mathrm{T}_{\min }$ field $\left({ }^{\circ} \mathrm{C}\right)$, at 2-m height. The corresponding top 5\% anomaly composites, after removing the summer average, are represented in b) Lisbon and (d). The precipitation rate anomaly field is represented only in those areas where such an anomaly is significant at the 5\% level (or 95\% confidence level) computed with a two-tailed t-test.

over Iberia from the SE-NW orientation of the SLP field to the more zonal E-W orientation for Lisbon and more meridional S-N for Madrid. A similar analysis was performed for the minimum temperature $\left(\mathrm{T}_{\min }\right)$ and results are shown in Fig. 7. Naturally, all dynamical fields associated with the 5\% composite remain unchanged, in particular, SLP and wind fields represented in Fig. 6. However, the impact on $\mathrm{T}_{\min }$ is considerably different from the one described for $\mathrm{T}_{\max }$. Not only is the magnitude of the impact smaller (notice the use of different scales in $\mathrm{T}_{\max }$ and $\mathrm{T}_{\min }$ composite and anomaly fields), but also the spatial location does change. In fact, $\mathrm{T}_{\min }$ anomalies associated with the 5\% composite for both cities are restricted to a smaller region in Southern Iberia (Figs. 7b and d). Only over Northern Morocco is the magnitude of the anomaly similar for both $\mathrm{T}_{\max }$ and $\mathrm{T}_{\min }$. It will be shown later that differences between $\mathrm{T}_{\max }$ and $\mathrm{T}_{\min }$ fields during EHD are associated with anomalously reduced precipitation (Fig. 8) and reduced cloud cover that are so characteristic of anticyclonic circulation.

This important discrepancy between Figs. 6 and 7 is related to the fact that $\mathrm{T}_{\max }$ is registered during daylight time (mid afternoon) and $\mathrm{T}_{\min }$ occurs generally before sunrise. Thus, during daytime enhanced solar short wave radiation further enhances the heating effect related to the advection of warm air, while during the night the strong clear sky emission of long wave radiation partially offsets that advection by cooling the lower troposphere (Trigo et al., 2004). This result implies an increase in the surface temperature range during EHD events.

In fact, the temperature range field for the 5\% composite reaches more than $22^{\circ} \mathrm{C}$ in Central Iberia, both for Lisbon and Madrid (Figs. 8a and c). However, it is over Western (Central) Iberia, the same location as the $\mathrm{T}_{\max }$ maximum, that the corresponding temperature range anomalous field reaches its maximum value of $5^{\circ} \mathrm{C}$ for Lisbon (Fig. 8b) and Madrid (Fig. 8d). Thus, we can state that the discrepancy between the impact on $\mathrm{T}_{\max }$ and $\mathrm{T}_{\min }$ is related to the absence of cloud cover over Iberia in most of these EHD episodes. If that is the case, then it should be possible to associate the lack of cloud cover with the absence of precipitation that also characterises EHD (Figs. 8a and c). In fact, for both cities, the impact on the precipitation rate is restricted to the 
western European region, from Morocco to Southern England, and its magnitude is most important in Northern Spain and in France, regions where summer precipitation is, on average, significant. Finally, this combined analysis on daily extreme temperatures provides evidence that EHD for these two Iberian cities are characterized by stronger anomalies for $\mathrm{T}_{\max }$ than for $\mathrm{T}_{\min }$.

\section{Discussion and conclusions}

The use of the same analysis and variables for two different cities has allowed one to identify the role played by some of the local variables in the association between extreme meteorological conditions and mortality. This paper reveals that those features that only depend on the underlying biology show almost the same values for both cities. This common pattern can be summarized as follows: $T_{\max }$ is the most relevant variable, with $\mathrm{T}_{\min }$ playing a secondary role. When $\mathrm{T}_{\max }$ surpasses a certain threshold, roughly the 95 percentile of its local distribution, then the impact on mortality increases dramatically. The triggering effect could be associated with failures in the adaptation mechanisms (Curreiro et al., 2002). This impact extends for up to 3 days after the EHD has occurred, while its maximum effect is observed the immediate day after.

Although local factors do not modify this basic pattern, it is shown here that they do influence the threshold value, which is highly dependent on location and climatology. In fact, the triggering threshold differs $2^{\circ} \mathrm{C}$ between coastal Lisbon and land-locked Madrid. Preliminary results for other important cities of Iberia located in warmer (Seville, Spain) and colder (Porto, Portugal) regions present this interesting characteristic: while their respective 95 percentile vary considerably, the triggering effect on excessive deaths is similar. We argue that the similarity of the curves above the triggering threshold could be associated with the intrinsic capacity for populations to accommodate for specific local conditions, as is shown in Naughton et al. (2002). The magnitude of the impact also reveals a high dependence on local variables. In our case, the shape of the temperature distribution and the greater demographic weight of elderly women explain the higher temperature impact.

Our results are within the range obtained in previous studies, although a direct comparison is not always easy due to the use of different methodologies. Nevertheless, a recent review study (WHO, 2004) shows that, for the Mediterranean area, the threshold values for $\mathrm{T}_{\max }$ may vary between $27^{\circ} \mathrm{C}$ for Turkey and $40^{\circ} \mathrm{C}$ for Malta. The time lag for the impact on mortality is rather homogeneous, ranging from 1 day or less in places like Malta, the Czech Republic or Serbia, up to 3 days in Greece. These values are compatible to those found in this paper. Interestingly, the role of relative humidity and $\mathrm{T}_{\min }$ shows a higher variability, thus in Turkey, the definition of heat wave includes a $\mathrm{T}_{\max }$ threshold of $27^{\circ} \mathrm{C}$, jointly with relative humidity higher than $40 \%$. Similarly, the heatwave definition for Serbia includes a threshold val- ues for both $\mathrm{T}_{\max }$ and $\mathrm{T}_{\min }\left(20^{\circ} \mathrm{C}\right)$. However, this double temperature threshold heatwave definition does not apply to relatively close countries, such as Greece, Malta or Turkey.

The climatological analysis reveals that the patterns generating EHDs are very similar at synoptic scales, but with decisive differences at local scale. Thus, small changes in the location of the $500 \mathrm{hPa}$ ridge or in the surface wind anomalies are the key factors leading to the occurrence of an EHD in a given city. However, while Madrid maxima require wind blowing directly from the south, transporting heat from Southern Spain and Northern Africa, Lisbon maxima occur under more easterly conditions, when Northern African air flows over the central Iberian plateau, which had been previously heated. As evidenced in this paper these small changes result in significant differences in the annual frequency of EHD and in the dating of the EHD within the same year. For Iberia, the typical air masses that provoke most excessive deaths are very hot and dry, as they have their source over the desert and not over the ocean.

These results can be applied for the real-time forecast of EHDs, since the current operational forecast of maximum temperatures is very accurate for a 1- to 3-day lead time. Thus, the forecast of a value above the identified threshold should provide enough time to trigger the implementation of suitable prevention mechanisms, such as those recently designed by the French authorities (http://www.sante.gouv.fr/).

Concern with heat events in Iberia is growing as a consequence of two factors: a) that the average, maximum and minimum temperature have risen in recent decades, and b) that most climate change studies suggest an increase of summer EHD in the Mediterranean region. Climate change results should always be analysed with extra caution, due to the large range of uncertainties involved. Nevertheless, the Third Assessment Report of the International Panel on Climate Change (IPCC, 2001) clearly states that it is now widely accepted that the global average temperature will increase over the next 100 years between $1.4^{\circ} \mathrm{C}$ and $5.8^{\circ} \mathrm{C}$, depending on the greenhouse gases emission and associated socioeconomic scenarios. There is also a generalised consensus that this increase will be larger over the continents than over the oceans (IPCC, 2001). Regional scenarios for the Mediterranean region indicate a non-constant increase of temperatures throughout the year (Trigo and Palutikof, 1999; Santos et al., 2002). Noticeably, temperatures in summer should rise more than in winter, further increasing the interseasonal cycle amplitude. In particular, results obtained with the regional model of the Hadley Centre (forced with the IPCC GGa2 scenario) for Lisbon indicate a large increase of summer (JJAS) $\mathrm{T}_{\max }$ from $28^{\circ} \mathrm{C}$ to roughly $34^{\circ} \mathrm{C}$, with the frequency of hot days (days with $\mathrm{T}_{\max }$ above $35^{\circ} \mathrm{C}$ ) increasing from the current figure of 5 to roughly 50 per year (Santos et al., 2002). Using these results, Dessai (2003) has estimated future heat-related mortality for Lisbon. Under all scenarios and assumptions employed mortality is expected to increase considerably, though acclimatization will reduce the burden. (See WMO (2004) for a recent update on the different factors al local and global scales which have a significant role 
in the association between mortality and extreme temperatures.) Besides the large uncertainties associated with the scenarios of $\mathrm{T}_{\max }$ increases, we must keep in mind the long time-span involved for these changes to take place $(\sim 100$ years).

It is a reasonable assumption to expect a slow, but effective adaptation capability from the affected populations, to accommodate these changes, thus diminishing considerably the associated hazardous health effects. Nevertheless, it is also reasonable to expect that the increase in frequency of days with $\mathrm{T}_{\max }$ above $38^{\circ} \mathrm{C}$ in Lisbon and Madrid will induce some impact on the health of both cities' populations. However, the definition of EHD used throughout this work is a flexible one, it adapts to specific local conditions (that is why the triggering threshold is so different between Madrid and Lisbon) and it should adapt to slow climate changes within the same location. For example, the shift of the entire $\mathrm{T}_{\max }$ distribution for Lisbon by $2^{\circ} \mathrm{C}$ or $3^{\circ} \mathrm{C}$ will inevitably implicate a new 95 percentile threshold (e.g. from $34.5^{\circ} \mathrm{C}$ to $37^{\circ} \mathrm{C}$ ), but it will maintain the number of EHD with $\mathrm{T}_{\max }$ above that threshold (5\%).

The results of this paper show that the forecast of maximum temperatures is not enough to obtain a realistic assessment of the human health impact of extreme temperatures on future climate scenarios, which would require one to take into account the following points:

1. Distribution of extreme temperatures, since they determine the threshold for the triggering effect and the magnitude of the impact.

2. Economic scenarios, which allow one to infer the use of domestic equipment, such as air conditioning.

3. Demographic scenarios, especially the proportion of women older than 65 years.

4. Local meteorological conditions vs. synoptic patterns, to obtain realistic downscaling schemes.

5. Mitigation due to acclimation mechanisms, mostly related to the speed of the temperature change.

Despite the large uncertainties involved throughout the complex process of climate scenario construction, they should be seriously considered by both countries' public health authorities, since in any case this will be a growing public health problem.

Acknowledgements. NCEP/NCAR reanalysis data were obtained from the Climate Prediction Centre. The Atlantic-European window used here was kindly provided by Ian Harris and David Viner from the Climatic Research Unit. The authors would like to acknowledge Isabel Trigo from CGUL for helpful suggestions on a earlier version of this paper. Spanish Instituto Nacional de Meteorología provided Meteorological data from Madrid. Two anonimous reviewers provided helpful comments which improved considerably the original manuscript.

Topical Editor O. Boucher thanks two referees for their help in evaluating this paper.

\section{References}

Alberdi, J. C. and Díaz, J. : Modelización de la mortalidad diaria en la Comunidad Autónoma de Madrid (1986-1991). Gac Sanit, 11, 9-15, 1997.

Alberdi, J. C., Díaz, J., Montero, J. C., and Mirón, I. J.: Daily Mortality in Madrid Community (Spain) 1986-1991: Relationship with atmospheric variables. Eur. J. Epidemiol, 14, 571-578, 1998.

Box, G. E., Jenkins, G. M., and Reinsel, C.: Time Series Analysis. Forecasting and Control. Englewood. Prentice Hall, 1994.

Curreiro, F. C., Heiner, K. S., Samet, J. M., Zeger, S. L., Strug, L., Patz, J. A.: Temperature and mortality in 11 cities of the Eastern of the United States. Am. J. Epidemiol, 155, 80-87, 2002.

Davis, R. E., Knappenberger, P. C., Michaels, P. J. and Novicoff, W. M. et al.: Changing Heat-related Mortality in the United States, Environ. Health Perspec., 111, 1712-1718, 2003.

Davis, R. E., Davis, R. E., Knappenberger, P. C., Michaels, P. J., and Novicoff, W. M. : Seasonality of climate-human mortality relationships in US cities and impacts of climate change. Clim. Res., 26, 61-76. 2004.

Dessai, S.: Heat stress and mortality in Lisbon. Part I: model construction and validation. Int. J. Biometeorol. 47, 6-12, 2002.

Dessai S.: Heat stress and mortality in Lisbon. Part II: an assessment of the potential impacts of climate change. Int. J. Biometeorol. 48, 37-44, 2003.

Díaz, J., García, R., Ribera, P., and Alberdi, J. C. et al.: A Modelling of Air Pollution and its Relationship with Mortality and Morbidity in Madrid (Spain). Int. Arch. Occ. Env. Health, 72, 366-376, 1999.

Díaz, J., López, C., Alberdi, J. C., Jordán, A., García, R., Hernández, E., and Otero, A.: Heat Waves in Madrid, 19861997: Effects on the health of the elderly. Int. Arch. Occ. Env. Health. 75, 163-170, 2002a.

Díaz, J., García, R., Velázquez de Castro, F., Hernández, E., López, C., and Otero, A.: Effects of extremely hot days on people older than 65 years in Seville (Spain) from 1986 to 1997. Int. J. Biometeorol, 46, 145-149, 2002b.

Donaldson, G. C., Keatinge, W. R., and Näyhä, S. et al.: Changes in summer temperature and heat-related mortality since 1971 in North Carolina, South Finland, and Southeast England. Environ. Res., 91, 1-7, 2003.

Frich, P., Alexander, L. V., Della-Marta, P., Gleason, P., Haylock, M., Klein Tank, A. M. G, and Peterson, T.: Observed coherent changes in climatic extremes during the second half of the twentieth century. Climate Res., 19, 193-212, 2002.

García R, Prieto, L., Díaz, J., Hernández, E., and del Teso, T.: Synoptic condition leading extremely high temperatures in Madrid. Ann. Geophys., 20, 237-245, 2002.

Greene, J. S. and Kalkstein, L. S.: Quantitative analysis of summer air masses in the eastern United States and an application to human mortality. Climate Res., 7, 43-53, 1996.

Grynszpan, D.: Lessons from the French heatwave. Lancet, 362, 1169-1170, 2004.

Guest, C. S., Wilson, K., Woodward, A., Hennessy, K., Kalkstein, L. S., Skinner, C., and McMichael, A. J.: Climate and mortality in Australia: retrospective study, 1979-1990 and predicted impacts in five major cities. Climate Res., 13, 1-15, 1999.

Huynen, M. M., Martens, P., Schram, D., Weijenberg, M. P., and Kunst, A. E.: The impact of the heat waves and cold spells on mortality rates in the Dutch population. Environ Health Persp., 109, 463-470, 2001. 
IPCC. Climate Change 2001: the scientific basis. Cambridge University Press, Cambridge, UK, 881, 2001.

Kalnay, E., Kanamitsu, M., Kistler, R., Colins, W., Deaven, D., Gandin, L., Iredell, M., Saha, S., White, G., Wollen, J., Zhu, Y., Cheliqh, M., Ebisuzaki, W., Higgins, W., Janowiak, J., Mo, K. C., Ropelewski, C., Wang, J., Leetmaa, A., Reynolds, R., and Jenne, J. D.: The NCEP/NCAR 40-years reanalyses project. Bull. Am. Meteorol. Soc., 77, 437-471, 1996.

Kalkstein, L. S.: A new approach to evaluate the impact of climate on human mortality. Environ. Health Perspect., 96, 145150, 1991.

Kalkstein, L. S. and Smoyer, K.: The impact of climate change on human health: some international implications. Experientia, 49, 469-479, 1993

Kalkstein, L. S., Jamason, P. F., Greene, J. S., Libby, J., and Robinson, L.: The Philadelphia Hot Weather-Health Watch/Warning System: Development and Application, Summer 1995. Bull. Am. Meteorol. Soc., 77, 1519-1528, 1996.

Karl, T. R., Jones, P. D., Knight, R. W., Kukla, G., Plummer, N., Razuvayev, V., Gallo, K., Lindseay, J., Charlson, R. J., and Peterson, T. C.: Asymmetric trends of daily maximum and minimum temperature. Bull. Am. Meteorol. Soc., 74, 1007-1023, 1993.

Keatinge, W. R., Donaldson, G. C., and Cardioli, E. et al.: Heat related mortality in warm and cold regions of Europe: observational study. Brit. Med. J., 321, 670-673, 2000.

Kelsall, J. E., Samet, J. M., and Zeger, S. L.: Air Pollution and mortality in Philadelphia, 1974-1988. Am. J. Epidemiol, 146, 750-762, 1997.

Khaw, K. T.: Temperature and cardiovascular mortality. Lancet, 345, 337-338, 1995.

Klein-Tank, A. M. G., Wijngaard, J. B., Können et al.: Daily dataset of 20th-century surface air temperature and precipitation series for the European Climate Assessment. Int. J. Climatol, 22, 14411453, 2002.

Koppe, C., Kovasts, S., Jendritzky, G., and Menne, B. et al.: Heatwaves: risks and responses. WHO Health and Global Environmental Change Serie ${ }^{\circ}$ 2. WHO Geneva, 123, 2004.

Kunst, A. E., Looman, C. W. N., and Mackenbach, J. P.: Outdoor Air Temperature and Mortality in the Netherlands. A time-series analysis. Am. J. Epidemiol, 137, 331-341, 1993.

Laschewski, G. and Jendritzky, G.: Effects of the thermal environment on human health: an investigation of 30 years of daily mortality data from SW Germany. Climate Res., 21, 91-103, 2002.

Luterbacher, J., Dietrich, D., Xoplaki, E., Grosjean, M., and Wanner, H.: European seasonal and annual temperature variability, tends and extremes since 1500 A. D., Science, 3, 1499-1503, 2004.

Makridakis, S., Wheelwright, S. C., and McGee, V. E.: Forecasting Methods and Applications. Wiley and Sons. S. Francisco. 1983.

Martens, W. J. M.: Climate change, thermal stress and mortality changes. Soc. Sci. Med., 46, 331-344, 1998.

McGeehin, M. A. and Mirabelli, M.: The potential impacts of climate variability and change on temperature-related morbidity and mortality in the United States. Environ Health Persp., 109, 185-189, 2001.

McGregor, G. R.: Winter ischaemic heart disease deaths in Birmingham, United Kingdom: a synoptic climatological analysis. Climate Res., 13, 17-31, 1999.

Montero, J. C., Mirón, I. J., Díaz, J., Alberdi, J.C.: Influencia de variables atmosféricas sobre la mortalidad por enfermedades respiratorias y cardiovasculares en los mayores de 65 años en la Comunidad de Madrid. Gac. Sanit. 11, 164-170, 1997.
Nakai, S., Itoh, T., and Morimoto, T.: Deaths from Heat-stroke in Japan: 1968-1994. Int. J. Biometeorol., 43, 124-127, 1999.

Naughton, M. P., Henderson, A., Mirabelli, M. C., and Kaiser, R. et al.: Heat-related mortality during a 1999 heat wave in Chicago. Am. J. Prev. Med., 22, 221-227, 2002.

North, G. R., Bell, T. L., Cahalan, R. F., and Moeng, F. J.: Sampling errors in the estimation of empirical orthogonal functions. Mon. Weather Rev., 110, 699-706, 1982.

Pan, W. H., Li, L. A., and Tsai, M. J.: Temperature Extremes and Mortality from Coronary Heart Disease and Cerebral Infarction in Elderly Chinese. Lancet 345, 353-355, 1995.

Pardo, A. and Ruiz, M. A.: SPSS11. Guía para el análisis de datos. Ed. McGrawhill, Madrid 2002.

Preisendorfer, R. W.: Principal Component Analysis in Meteorology and Oceanography. Developments in Atmospheric Science, 17, Elsevier, 1988.

Sáez, M., Sunyer, J., Castellsagué, J., Murillo, C., Antó, J. M.: Relationship between Weather Temperature and Mortality: A time series analysis approach in Barcelona. Int. J. Epidemiol., 24, 576$582,1995$.

Santos, F. D., Forbes, K., and Moita, R.: Climate Change in Portugal. Scenarios, impacts and Adaptaion Measures - SIAM. Gradiva, Lisbon, 2002.

Sartor, F., Snacken, R., Demuth, C., and Walkiers, D.: Temperature, Ambient Ozone Levels and Mortality during Summer 1994 in Belgium. Environ. Res., 70, 105-113, 1995.

Schär, C., Vidale, P. L., Lüthi, D., Frei, C., Häberli, C., Liniger, M. A., and Appenzeller, C.: The role of increasing temperature variability in European summer heatwaves, Nature, doi:10.1038/nature02300, 2004.

Smoyer, K. E.: A Comparative Analysis of Heat-wave Associated Mortality in St. Louis, Missouri-1980 and 1995. Int. J. Biometeorol., 42, 44-50, 1998.

Tobías, A., Díaz, J., Sáez, M., and Alberdi, J. C.: Use of Poisson regression and Box-Jenkins models to evaluate the short-term effects of environmental noise levels on daily emergency admissions in Madrid, Spain. Eur. J. Epidemiol., 17, 765-771, 2001.

Trigo, R. M. and Palutikof, J. P.: Simulation of daily temperatures for climate change detection over Portugal: A neural network model approach. Climate Res., 13, 45-49, 1999.

Trigo, I. F., Bigg, G. R., and Davies, T. D.: Climatology of cyclogenesis in the Mediterranean. Mon. Weather Rev., 130, 549-569, 2002.

Trigo, R. M. and Palutikof, J. P.: Precipitation scenarios over Iberia: a comparison between direct GCM output and different downscaling techniques. J. Climate, 14, 4422-4446, 2001.

Trigo, R. M., Trigo, I. F., DaCamara, C. C., and Osborn, T. J.: Climate impact of the European winter blocking episodes from the NCEP/NCAR Reanalyses. Climate Dynamics, 23, 17-28, 2004.

Ungar, S.: Is Strange Weather in the Air? A Study of U.S. National Network News Coverage of Extreme Weather Events. Climatic. Change, 41, 133-150, 1999.

Wilks, D. S.: Statistical Methods in the Atmospheric Sciences: an introduction. Intern. Geophy. Ser., 59, Academic Press, 1995.

WHO Heat-waves: risks and responses. Health and Environmentl change. WHO Series N ${ }^{\circ}$, Geneva, 2004. 